\title{
Transatlantic Interaction with European Project Semester
}

\section{Dr. Duane L. Abata, South Dakota School of Mines and Technology}

Dr. Abata has worked in academia for over thirty years at universities and with the Federal government around the country. He began his career at the University of Wisconsin, served as Associate Dean and Dean at Michigan Technological University and then at the National Science Foundation in Washington, D.C. as program manager in the Engineering Directorate. From 2003 to 2004, Dr. Abata was President of the American Society for Engineering Education. Following his appointment at NSF he served as Dean of Engineering and Engineering Technology at Northern Arizona University and Dean of Engineering at South Dakota School of Mines and Technology. Dr. Abata organized and was successfully awarded a research center in bioenergy, CBERD, funded by the National Science Foundation. Dr. Abata is currently the Executive Director of this industry-university consortium. In addition to this research center, Dr. Abata is active with international engineering education and participates in an ten university consortium in the European Union that provides international engineering design opportunities for students in engineering and science. His area of research is bioenergy utilization and combustion.

\section{Dr. Arvid Andersen \\ Dr. Wayne B. Krause, South Dakota School of Mines and Technology}

Dr. Wayne B. Krause is a semi-retired professor emeritus (mechanical engineering) at the S. D. School of Mines and Technology (SDSM\&T). He currently teaches thermal science courses in the department. Dr. Krause has been involved in engineering education for over 35 years. Previously, he was head of the mechanical engineering department and later he was dean of one of the colleges at SDSM\&T. Dr. Krause is a life member of ASME and a registered professional engineer in South Dakota. Dr. Krause obtained his doctoral degree from the University of Nebraska-Lincoln and his BSME and MSME from SDSM\&T. 


\title{
Transatlantic Interaction with European Project Semester
}

\begin{abstract}
This paper describes successful interaction between engineering colleges in the United States and similar institutions engaged in the European Project Semester program, EPS, throughout Europe. This interaction involved both participation of teaching and international student exchange. The EPS program described herein was designed to promote student exchange and student interaction between EPS institutions in a multidiscipline environment in Europe. The primary purpose of EPS is to address engineering design in junior and senior years. As a coincidental result several students from the United States have participated in this primarily European program for the benefit of broadening the educational and career horizons of these students as well as gain valuable insight to international approaches of engineering design. In every case students from the United States have commented that their experience was significant however meeting engineering senior design requirements in some cases has been problematic due to interpretation of ABET senior design requirements.
\end{abstract}

\section{Introduction}

European Project Semester, or EPS, is an international exchange program specifically designed to address the design component of engineering students during their junior year. The program is highly successful and involves eleven engineering schools in nine countries throughout Europe. The program originated in 1995 in Elsinore (Helsingør) Denmark by one of the coauthors of this paper. He observed that his engineering students were lacking in international exposure with continental Europe. He then devised a scheme where engineering students from continental Europe would visit his university and work together with Danish students on cultural broadening and engineering design for a semester. Originally, EPS was formed with a meager beginning involving only a few visiting students and, a few years later, moved to the Engineering College in Copenhagen with funding from the Danish government ${ }^{1}$. Popularity of the program grew substantially over the following years as other engineering colleges recognized the educational benefits of international exchange (see Figure 1). Too, this international exchange was promoted by the European Union through the Washington Accord ${ }^{2}$ which began to encourage a unified approach to engineering education. Over three hundred students from forty countries participate in this exchange program each semester at eleven engineering college sites forming a significant network of international engineering education exchange.

The EPS programs are tuition free for participating students which is in alignment with most public colleges and universities throughout Europe. Students must pay for travel and living expenses in the receiving country. Travel expenses are not prohibitive because of the proximity of neighboring countries in Europe and well developed mass transportation. Living expenses are somewhat comparable. Small grants are available from an EU cooperation called ERASMUS to encourage student participation from countries where students may not have the economic means 
to participate in the program. European sites are funded by individual governments, the European Union, and the participating colleges.

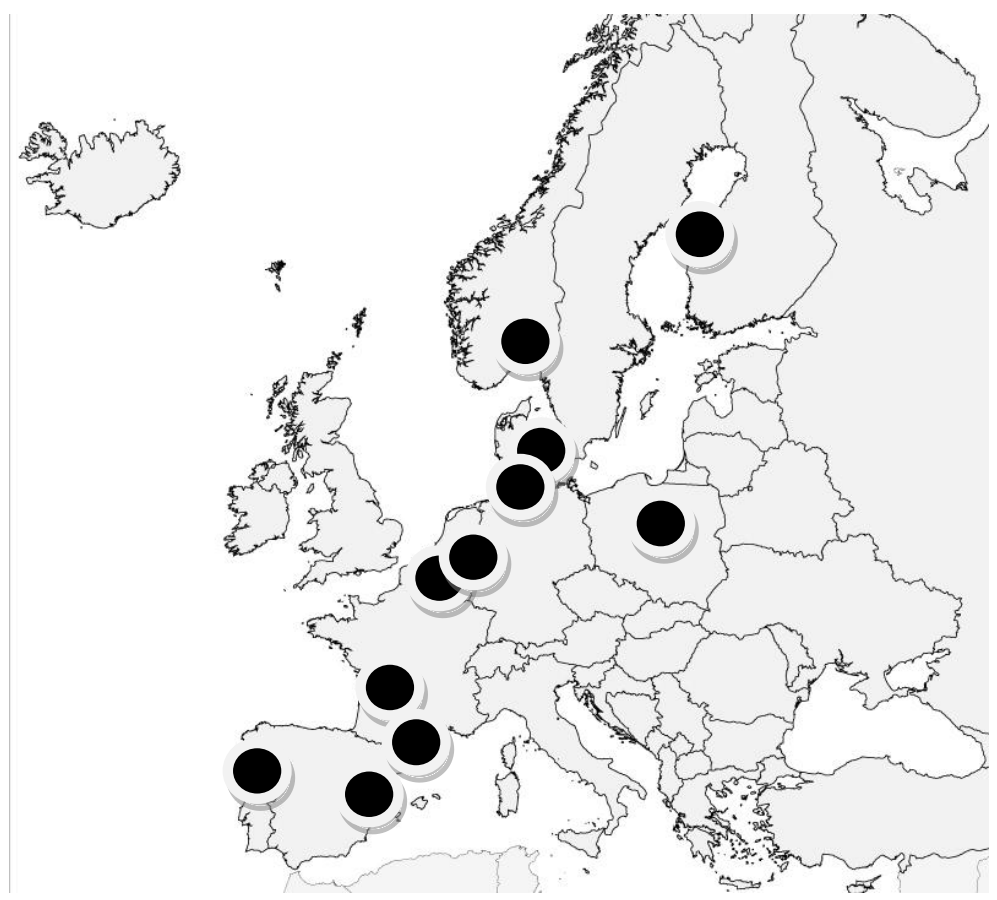

Figure 1. EPS Sites

It is interesting to note that individual EPS programs are not formally coordinated through a central governing body but that coordination is sound - achieved through frequent communication and cooperation by site directors. Site directors are mutually committed by the inherent nature and necessity of the overall program. Professional friendships are also a significant driving force that keeps the overall program on track. An annual coordination meeting (EPS Providers) is scheduled usually in December at one of the EPS sites. This voluntary meeting rotates around the participating countries and usually involves fifteen to twenty participants. New concepts, difficulties, and solutions are typical agenda items. As the annual meetings rotate each year, individual site directors become familiar with each of the programs and physical facilities. An important part of the annual EPS Providers meeting is approval of new EPS sites.

\section{Language and Structure}

Classes in EPS are taught in English thus eliminating a major barrier to international exchange. While almost all European students are multilingual, English is recognized as a base language understood by most. Participating students show reasonable proficiency in English during the application process. As mentioned previously, the popularity of the program is such that the program is successfully promoted by word of mouth. Each site does have its own corresponding website that details the application process. 
The structure of the program is non-traditional in that students remain as a cohort throughout the semester. Students often remain in one large classroom of reasonable size to accommodate both instruction and design team networking (design lab). Instructors visit the classroom according to a predetermined schedule that varies daily or students may move to other classrooms as a cohort. In this way instructors participate in EPS instruction in block intervals allowing each instructor to continue with normally scheduled traditionally taught classes that are not part of the EPS experience. This block scheduling also allows flexibility for visiting instructors that may travel from one EPS site to another. A typical block scheduling scheme is shown below ${ }^{3}$.

\begin{tabular}{|c|c|c|c|c|c|c|c|c|c|c|c|c|c|c|c|c|}
\hline Activity Study week & 1 & 2 & 3 & 4 & 5 & 6 & 7 & 8 & 9 & 10 & 11 & 12 & 13 & 13 & 15 & 16 \\
\hline Introduction, team building & & & & & & & & & & & & & & & & \\
\hline Project management & & & & & & & & & & & & & & & & \\
\hline Project planning & & & & & & & & & & & & & & & & \\
\hline Languages & & & & & & & & & & & & & & & & \\
\hline Systematic innovation & & & & & & & & & & & & & & & & \\
\hline EU-law and Property Rights & & & & & & & & & & & & & & & & \\
\hline Cross-Cultural Communication & & & & & & & & & & & & & & & & \\
\hline Environmental Subjects & & & & & & & & & & & & & & & & \\
\hline International Marketing & & & & & & & & & & & & & & & & \\
\hline Communication skills & & & & & & & & & & & & & & & & \\
\hline Project Review & & & & & & & & & & & & & & & & \\
\hline Interim report & & & & & & & & & & & & & & & & \\
\hline Project work & & & & & & & & & & & & & & & & \\
\hline Examinations & & & & & & & & & & & & & & & & \\
\hline Graduation & & & & & & & & & & & & & & & & \\
\hline
\end{tabular}

Figure 2. Typical block scheduling scheme for EPS

It is possible to interpret the diagram in Figure 2 to arrive at class time devoted to each topic. EPS students meet for approximately seven hours per day for five days per week. Three topics are covered during the first week. Thus students receive approximately 11-12 hours of exposure for each subject (Team Building, Systematic Innovation, and Communication Skills).

The semester is a recognized 30-credit unit course under the European Credit Transfer System (ECTS).Project work comprising the bulk of the semester long design experience amounts to 25 credit units, and short intensive courses cover the remaining points. It is generally assumed that 2 ECTS credits equal one course credit in the United States following ABET guidelines. Thus the EPS experience is roughly equal to 12-13 U.S. credits, or that of a full time student. 
The final grade is determined by the technical content of the report assessed by an individual examination of each student.

Students receive three grades for the overall EPS experience: one grade for the project, one for the language courses, and one for all the other courses. The final grades are thus both objective and subjective in that attendance and participation are included in the final evaluation. Students are critically evaluated. Students failing to meet the minimum guidelines are either issued 'nocredit' for their experience or are asked to return the following semester if sufficient reason is provided for poor performance (illness, language difficulties, lack of background, etc.).

\section{EPS and Experiential learning}

The educational process in the EPS program is best described as experiential learning. Experiential learning is most easily described as the process of acquiring information through the study of a subject without the necessity for direct textbook exposure. In the early 1970s, educational researchers David Kolb and Ron Fry developed the Experiential Learning Model $(\mathrm{ELM})^{4}$ which is composed of four elements:

- concrete experience

- observation of and reflection on that experience

- formation of abstract concepts based upon the reflection

- testing the new concepts

- (repeat)

These four elements are the quintessence of a spiral of learning that can begin with any one of the four elements, but typically begins with a concrete experience. The model was named to emphasize links to ideas from Piaget ${ }^{5}$, et. al., and other writers of the experiential learning paradigm. This model was developed predominantly for use with adult education, but has found widespread pedagogical implications in higher education.

There are certain characteristics of a student (or a group of students) that are essential to bring the experiential learning model to a satisfactory end. These are:

1. the learner must be willing to be actively involved in the experience;

2. the learner must be able to reflect on the experience;

3. the learner must possess and use analytical skills to conceptualize the experience; and

4. the learner must possess decision making and problem solving skills in order to use the new ideas gained from the experience.

The dimensions of experiential learning are analysis, initiative, and immersion which describe the EPS atmosphere nicely. Once students are identified with a project, they proceed to analyze with the skills they have learned earlier and skills they acquire in the EPS classroom setting. Self learners having strong academic skills are identified during the application process; thus initiative is inherent in the EPS student body. It should be noted that most European students are self learners since semester grades are based not upon hourly exams at regular intervals but rigorous oral and written examination. Finally, students in EPS are completely immersed; the 
one room learning environment and interaction with each other on a analytical, cultural, and social basis is evidence of this immersion experience. Language and cultural barriers are overcome with understanding, thorough communication, and interpersonal reward. ${ }^{678}$ Though both methods (experiential and traditional classroom) aim at instilling new knowledge in the learner, academic learning does so through more abstract, classroom based techniques, whereas experiential learning actively involves the learner in a concrete experience.

\section{General Observations}

One of the co-authors of this paper is the founder of the EPS program and is now Professor Emeritus of mechanical engineering in Copenhagen. The primary author of this paper served as a guest lecturer in the EPS program at two sites for twelve years (Oslo and Copenhagen). He also acted as U.S. liaison with EPS site directors during this period and attended many of the annual meetings held at various EPS locations. This was a time of significant growth of the program. Between 1999 and 2011 student attendance at the Copenhagen site grew from just under forty students to nearly eighty students. Six EPS sites throughout Europe were added during this period as well.

In his academic and administrative roles during this period the primary author worked with students and faculty members to encourage student participation from the United States resulting in a small but steady flow of student exchange. Memorandums of Understanding between universities and colleges in the United States and each of the EPS sites are necessary because the EPS program is tuition free funded by the European constituency and engineering programs in the United States are tuition and fee based. These formal memoranda establish a one-to-one reciprocal student exchange allowing tuition transparency for participating students. (On a mutually beneficial note, these memoranda have encouraged many students from Europe to attend a semester of study in the United States.)

An EPS class at one of the sites typically ranges from about twenty students to eighty students with the average size closer to the low end of twenty to thirty students. Not all sites offer EPS both semesters. In a EPS class of thirty students one can expect to find representation from ten to fifteen countries. EPS directors have found that selecting two or three students from a country increases the success and satisfaction rate since strange surroundings (different cultures) are better understood and accepted with a supporting colleague. Attention is also placed on student background and major area of study. Potential design projects are established before the admission process; thus student selection is also based upon the student selecting a satisfactory design experience that will meet his or her academic and interest needs.

The typical EPS class then is composed of students from a variety of engineering study areas and different cultural and linguistic backgrounds with the common goal of engineering design. Students in teams of $2-4$ are assigned a design project based upon their interest identified during the application process. EPS students are generally very mature, eager to learn, and, because of the international setting they themselves are exposed to in everyday life, very 
respectful of international lecturers and visitors. There is an expected struggle with expression as students converse in a language other than their mother tongue. (U.S. students learn quickly that patience and compassion are part of the EPS experience. U.S. students also learn rather quickly that their multilingual shortcoming is a handicap.) During a lecture a low level of chatter is experienced as students ask fellow colleagues for help with interpreting the lecturer's words, and page through dictionaries to assist with translation. Despite the maturity level of the students, attention span is somewhat limited so it is essential that lectures are punctuated with numerous breaks, discussion, and possibly brief 'hands-on' assignments.

One of the most important yet easily missed observations is that students from different cultures think differently. The approach to a design problem (a problem having a design solution instead of a single numerical answer) is taken from different perspectives. Solutions too are obviously different and representative of the background of a student; together in teams this results in what can be termed 'collective creativity' of a interdisciplinary and multicultural capstone experience.

The social aspect of a multicultural group of eager college age students is yet another valuable component in the EPS experience. Social gathers and interactions are not formal nor part of the program structure. They appear spontaneously and with great enthusiasm. It is not uncommon for groups of five to ten students to travel together on the weekends to historic or picturesque sites, or events that pleasantly saturate the European continent. Travel by train is often the choice of these weekend experiences. Lodging may be in the parent's home of one of the students. Friendships formed during the EPS experience (now in its twentieth year) are frequently life-lasting.

Exit Interviews of U.S. students have been routinely conducted by the primary author of this paper. Interview questions, presented to the student in an informal manner, typically are:

- What specifically did you learn about the design process?

- What other academic knowledge and skills have you experienced?

- What did you learn about team building and team interaction?

- What credit transfer do you expect or have already received by your home institution?

- Finally, did you enjoy your EPS experience?

About forty students were interviewed through the years from three institutions. The response to this survey has been overwhelmingly positive although in at least one instance a student commented that it was not what he expected and that the experience was less than satisfactory. Other students have consistently commented that credit transfer is problematic (discussed below). Probably the best expressions of support come from testimonials of students which, in some instances, have been documented:

'Let me start by saying that I cherish this experience as much as I do my four years at Notre Dame. I have learned more about myself, the world and life in the last five 
months than I have in my previous 24 years of living. I came to the program believing that with my credentials and experience, I would be able to easily succeed in this setting. I have never been so wrong in my life. My error was in that while I have experience working with Americans of various ages and egos, we are all American and therefore predominantly of the same mindset. When I started working within a multi-national team, I found myself having to reinvent my work habits, my communication skills and my choice of words. It was one huge and complete paradigm shift.' - a mechanical engineering graduate from Notre Dame.

Although choice of words and subject vary, the above testimonial is typical of many gathered over the years. There appears almost a re-birth of thought and enlightenment that occur within the student. This positive experience is one that is carried back and shared with other students unable or not interested in participating. The experience (and investment) is multiplied many times over.

\section{Barriers Encountered by U.S. students}

The EPS experience is a good one but not for everyone. There are several barriers encountered by U.S. students that are both self generated (or self imposed) and institutionally imposed. Some of the more common barriers are expressed below.

Funding. The cost of EPS to U.S. students may be prohibitive. While maintenance costs (living expenses) are about the same, except in the Scandinavian countries where such expenses are a bit higher, transportation costs to and from EPS are high. A typical airline ticket may cost, in today's currency, over a thousand dollars. While this investment is not prohibitive in the overall scheme of one's education, it falls at a time when many U.S. students struggle with ever rising tuition and fees at U.S. institutions. There are additional costs associated with initial transportation and settlement in the new environment. EPS programs also require an upfront $\$ 5000$ deposit which ensures the receiving EPS site reimbursement for unexpected difficulties such as early return, health issues, etc. This deposit is held in a security account and returned at the end of the exchange. At some sites this deposit remains in the student's or parent's account with appropriate documentation from a U.S. monetary institution.

Visas. While visa requirements were somewhat lax in the early stages of the EPS program, it has now become essential that all U.S. students have travel visas because the semester length is longer than that of tourist status. Visas have become a challenge. In many cases students must apply for a visa, travel in person to an embassy (or consulate) for an interview that may last no longer than five to ten minutes, and return to their home institution to wait for approval which may take as long as several months. Passports are, of course required before the visa application and passport application may require a month or more for processing.

Fear of the Unknown. Students interested in the international experience are self driven. Yet there is an inherent fear that this investment may not work or adjustment may be difficult or insurmountable. This is particularly true of engineering students which by nature are cautious 
and lack risk-taking skills. Language is part of this fear. While EPS is taught in English students are apprehensive about language barriers in a foreign land. For the most part this is self imposed as many Europeans in larger cities have some knowledge of the English language. U.S. students with some language skills in German, Spanish, or French, are less intimidated. Quite obviously, the adventurous student is more likely to seek an international experience, particularly with encouragement from members of the faculty or from a parent.

Credit Hour Transfer. This is may be one of the most difficult barriers with U.S. students participating in EPS. Credit earned by students participating in EPS is based upon the European Credit Transfer and Accumulation System (ECTS). Students earn 30 ECTS. Exchange agreements between participating countries in EPS must agree to this 30 ECTS policy with exception to students from the United States. This exception is made to encourage U.S. participation but may be problematic since many here in the U.S. do not or are not willing to understand the ECTS system. Roughly 2 ECTS equals one credit hour in the United States. Through the memorandum of agreement with their institution, a U.S. student must pay the usual tuition directly to their home institution to allow for this one-to-one exchange. Generally, credit transfer approval does not take place until the student returns with transcripts in hand. In many instances, a student may receive only a small number of transfer credits (i.e., a student pays a full 12 credit tuition but may receive only three to six transfer credits). This credit transfer issue is embedded in: 1)the student's ability to convince his/her advisor and department head, and 2)the innate fear that an ABET program evaluator will recognize and discount this credit transfer during the ABET review process. This latter point is sufficient for administrators to error always on the side of caution. This is particularly true at institutions that are conservative in nature even though international exposure is clearly enunciated and encouraged in ABET criteria. ${ }^{9}$ This has an added negative effect in that certain faculty members, particularly at conservative institutions, may actually discourage international exchange programs and dismiss such programs as a waste of time. Members of the faculty look for content rather than experience. Recall (described earlier in this paper) the EPS program is not traditionally structured with regular classes and with traditional course numbers.

Housing. Students traveling abroad face the problem of finding suitable housing for the semester. Since all students enrolled in an EPS program are, by definition, international, all EPS sites have systems in place to streamline or alleviate this difficulty. In most instances housing is found by EPS assistance ahead of the exchange. This is one of the major benefits EPS has over many other semester exchange programs.

Design Project Selection. During the application process a student identifies three projects of interest based upon a paragraph description. Teams are organized at least one month before the start of EPS based upon student interest. Students receive an email informing them of their project and project team before they arrive on campus and are asked to discuss the project with a professor or supervisor at their home university. In this way the student is aware of the amount of work required to receive proper credit by his/her home university. Soon after arriving to the 
EPS site students are strongly encouraged to further discuss their projects and teams with their home supervisors so that projects can be further refined to meet home university requirements. At this critical time students also meet with their design teams and their project supervisors to ensure proper subject material, depth, and breadth is reached for home university requirements. While this process is detailed and EPS site directors try their best to place the student on a relevant design project, the design project assignment may or may not reflect the actual needs of the student. Students too may not be fully knowledgeable of the design depth requirement at their home institution. In some instances design projects are not convincingly sufficient to meet home institution requirements. Advanced advising at the home institution is essential but considering the many steps and barriers involved in the application process this is often overlooked.

One Semester Design Experience. EPS is a semester long design experience. Many capstone design requirements in the U.S. are two semesters in length. There is always the question as to whether this one semester experience will count toward the capstone design requirement in the U.S.

Academic Calendar Differences. There are significant differences in the U. S. and European academic calendars, and these calendars differ from institution to institution. European calendars begin earlier in the Fall semester but like U.S. calendars, run to the Christmas holiday period. European calendars may begin earlier or later in the Spring semester and may run to early June. U.S. students seeking summer employment are thus compromised and summer employment may be essential to meet tuition, fee, and living expenses for the coming academic year.

\section{EPS Model in the United States}

The United States, while superficially viewed as a homogenous culture (a melting $\operatorname{pot}^{10}$ ) it is anything but that. Although we are tied together by a common government and a common language there are significant regional differences as any astute traveler will attest. The culture of the urban environment of the East Coast differs significantly from the rural Midwest Plains. The progressive culture of the California coastline is vastly different from the conservative cultures of the West or South. Engineering students are extremely mobile during their initial careers oftentimes leaving a small engineering college in rural America for the hustle and bustle of a large urban city. Many students have difficulty with adjustment and many leave their initial career choices after only a few years.

It would seem reasonable and logical that the EPS model would work nicely in the United States where such an exchange program, formally structured, would add significantly to their academic experience. Students in South Dakota might spend a semester (or year) at an institution in New York and vice versa. This concept was proposed to the Deans Engineering Council of ASEE several years ago and received reasonable support ${ }^{11}$. There are however significant barriers to such a venture and these barriers are probably insurmountable. 
Funding. Most public engineering colleges and universities in Europe are funded by their respective central governments. There is an altruistic desire to make education available to all at little or no cost (which is reflected in higher taxation rates). Public engineering colleges and universities in the United States are, of course, funded partially by the States and partially by tuition and fees oftentimes with general funds augmented by indirect charges on research grants and contracts. Some public institutions are also partially funded by large endowments. Funding for a like-EPS program is necessary to provide infrastructure (faculty release from normal teaching duties, classroom facilities, and necessary administrative tasks). There are only a few opportunities for federal funding from such agencies as the U.S. Department of Education or the National Science Foundation. The former (DOEd) provides limited opportunities to augment novel approaches to engineering education (such as the DOEd FIPSE program and these opportunities are very specific. The latter (NSF) provides opportunities in research including pedagogical research as mandated by their federal charter ${ }^{12}$. Funding for such an undertaking as a like-EPS program would require a ten year commitment which is not likely in the yearly fiscal cycle. Industrial funding could be a possibility but such coordination and commitment would be a tremendous undertaking and highly improbable.

Enrollment Competition. Competition for enrollment in academic programs, including engineering, poses yet another challenge. Public (and private) universities rely heavily on enrollment numbers for tuition and fee income which is a significant component of the general fund of a university. While an exchange program as that described would essentially be transparent there is a perceived risk that students may not return to their home institutions resulting in loss of income. It is an inherent characteristic of competition to avoid any damage, perceived or otherwise. This difficulty could only b overcome when university presidents (or chancellors) embrace this effort and communicate their conviction to administration and faculty.

The Conservative Nature of ABET. While one of the underlying themes of ABET 2000 was to inspire innovative techniques in engineering education our accreditation body ABET inherently promotes traditional approaches to engineering education. The structure of the ABET process is driven by the professional societies and industrial representatives. The accreditation process occurs after the academic program is in place, not before. Since accreditation is highly valued (rightly so). Program evaluators are selected from both industry and academia. Program evaluators may not view a novel and non-traditional program such as that described here in the best of light. Consequently engineering colleges and universities are highly reluctant to venture into the unknown without adequate incentive. Rather, the conservative approach is more the norm.

At this conjuncture it is relatively safe to say that unless there is a very strong incentive to formulate and put into place a reasonable like-EPS program here in the United States such a venture is unlikely to happen or evolve into the rich networked program offered by European Project Semester. While this relatively negative statement may seem as though this novel approach should be abandon nothing should be further from such an educational outcome. There 
are always possibilities of creative and acceptable approaches. These authors remain committed to evolutionary improvements in our engineering educational system.

\section{Summary}

This paper briefly describes the formation of a novel and successful program now in-place and fully operational in Europe called the European Project Semester, or EPS. This program had meager beginnings at one small engineering program in Denmark and now encompasses eleven engineering colleges in nine European countries with an annual enrollment of over 600 students. EPS encourages student exchange from all European countries, China, Japan and the United States. While there has been interest and participation by U.S. students; almost all have found their EPS experience extremely positive. There are several hurdles that U.S. students must accept and overcome; these hurdles are not insurmountable but may require investment of both time and money. Nevertheless, energetic and venturous U.S. students have an opportunity with EPS that will enhance their career interactions on the global playing field of today's economy and enlighten their understanding of the many cultures and people that make up the engineering international community. While this EPS program could be adapted to the United States to bring together differences in regional cultures and creative problem solving, it is unlikely to occur under the present circumstances due to funding constraints, the individualist nature of the American physique, and the conservative nature of the accreditation process.

\section{References}

${ }^{1}$ As of January 1, 2013 IHK has merged with DTU (Technical University of Denmark). The Engineering College is actually located in Ballerup which is about a fifteen minute train ride from Copenhagen city center.

2 "Washington Accord", International Engineering Alliance. International Engineering Alliance. http://www.washingtonaccord.org/Washington-Accord/signatories.cfm. Retrieved 20 December 2012

${ }^{3}$ From http://int.ihk.dk/exchange-students/european-project-semester/european-project-semester\#What_is_EPS_, viewed 20 Dec 2012.

${ }^{4}$ Kolb. D. A. and Fry, R. (1975) Toward an applied theory of experiential learning. in C. Cooper (ed.), Theories of Group Process, London: John Wiley

${ }^{5}$ Beilin, H. (1992). "Piaget's enduring contribution to developmental psychology". Developmental Psychology 28 (2): 191-204.

${ }^{6}$ Itin, C. M. (1999). Reasserting the Philosophy of Experiential Education as a Vehicle for Change in the 21st Century. The Journal of Experiential Education 22(2), 91-98.

${ }^{7}$ Merriam, S. B., Caffarella, R. S., \& Baumgartner, L. M. (2007). Learning in adulthood: a comprehensive guide. San Francisco: John Wiley \& Sons, Inc. 
${ }^{8}$ Hutton, M. (1980). Learning from action: a conceptual framework, in S. Warner Weil and M. McGill (eds) Making Sense of Experiential Learning.. Milton Keynes: SRHE/Open University Press. pp. 50-9, p.51.

${ }^{9}$ ABET Criteria 3 (a through $\mathrm{k}$, particularly h) http://www.abet.org/DisplayTemplates/DocsHandbook.aspx?id=3143, viewed 23 Dec 2012.

${ }^{10}$ Celebrating Our Nation's Diversity, United States Bureau of the Census, CBET 95/01 (1995)

${ }^{11}$ Engineering Deans Council, American Society for Engineering Education, a representative body of engineering deans throughout the country that meet regularly at the ASEE Annual Conference and at the Engineering Deans Institute, another ASEE conference event, semi-annually.

${ }^{12}$ Private communication with both the Office of International Science and Engineering and with the Division of Engineering Education and Centers at the National Science Foundation.

${ }^{13}$ Andersen, Arvid. (2009): Keynote on Project Management and Teamwork. Proceedings of the First IberoAmerican Symposium of Project Approaches in Engineering Education (PAEE 2009), University of Minho, Guimaraes 2009. ISBN 978-972-8746-74-2

${ }^{14}$ Macukow B., Saryusz-Wolski T. (2008) Facilitating Multidisciplinary Projects in International Teams. TREETeaching and Research in Engineering in Europe Special Interest Group B3.

${ }^{15}$ Andersen, Arvid, J., (2000) Assessment Techniques used in Multidisciplinary and Cross-Cultural Student Teamwork. Proceedings ASEE Annual Conference June 18-21, St. Louis, MO, USA

${ }^{16}$ Andersen, A., (2001); Implementation of Engineering Product Design Using International Student Teamwork to Comply with Future Needs, EJEE, 26: 179 - 186.

${ }^{17}$ Andersen, Arvid (2003) Collaborating Learning in Interdisciplinary and Intercultural Teams. 3rd International Conference on Engineering and Computer Education, March 16-19, 2003, Sao Paulo, BRAZIL.

${ }^{18}$ Andersen, A., (2004): Preparing engineering students to work in a global environment to cooperate, to communicate and to compete, EJEE, 29: 549 - 558.

${ }^{19}$ Andersen, A., (2004): Student based learning in a multicultural environment, ASEE, Annual Meeting.

${ }^{20}$ Chojnacka, E., Saryusz-Wolski, T., Macukow, B., Andersen, A. (2000): Cross-Cultural Communication in Engineering Education, Proc. SEFI Annual Meeting Paris.

${ }^{21}$ Gesteland Richard R. (2002) Cross-Cultural Business behavior. Third Edition Copenhagen Business School Press

${ }^{22}$ Tranter Ian, Bond Kay, (1997) QFD: Embodying Best Practice Approaches for the Inexperienced Designer Third International Symposium on QFD, 1st-2nd of October. Linkøping, Sweden 